\title{
FATTY ACID COMPOSITION OF THREE SMALL INDIGENOUS FISHES OF BANGLADESH
}

\author{
Tonima Mustafa*, M. Niamul Naser ${ }^{1}$, Sabrina Murshed ${ }^{2}$, Zeba Farhana ${ }^{3}$, \\ Mushfida Akter ${ }^{4}$ and Liaquat Ali ${ }^{4}$ \\ Department of Zoology, Jagannath University, Dhaka, Bangladesh
}

\begin{abstract}
The total fat and fatty acid composition of three commonly consumed small indigenous fish species of Bangladesh, Mola, Amblypharyngodon mola, Jat puti, Puntius sophore and Shar puti, Systomus sarana. Twenty-one types of fatty acids were identified from the extracted oil of these fishes. C16:0 and C18:0 were the predominant saturated fatty acids (SFA), C16:1 $\omega_{7}$ and $\mathrm{C} 18: 1 \omega_{9}$ the main monounsaturated fatty acids (MUFA), while C22:6:4 $\omega_{3}$ (DHA), C20:5 $\omega_{3}$ (EPA) were the main PUFAs. The total $\omega_{3}$ was between $4.28 \%$ to $17.86 \%$ and the total $\omega_{6}$ was between $4.08 \%$ to $23.12 \%$. The $\omega_{3} / \omega_{6}$ ratio was between to $0.35 \%$ to $1.50 \%$. It is evident from this study that A. mola, $P$. sophore and S. Sarana are good source of $\omega_{3}$ and $\omega_{6}$ PUFA and their regular consumption will contribute to better health.

Kew words: Small indigenous fishes, Fatty acid composition, Bangladesh.
\end{abstract}

\section{INTRODUCTION}

Polyunsaturated fatty acids (PUFAs), especially $\omega_{3}$ and $\omega_{6}$ fatty acids have a major role in health and disease. In the past two decades, perhaps the single most important dietary recommendation to improve human health and prevent chronic disease is to increase our dietary intake of $\omega_{3}$ fatty acids which are found primarily in fish. Researchers have shown that $\omega_{3}$ fatty acids reduce the risk of heart disease. In addition to reducing the risk for heart disease, regular consumption of fish or supplemental $\omega_{3}$ fatty acids may be helpful in preventing, treating, or improving a wide variety of diseases and disorders, including inflammatory diseases, rheumatoid arthritis, inflammatory bowel disorders (Crohn's disease, ulcerative colitis), periodontal disease (gingivitis), mental disorders (autism, depression, bi-polar disorder, borderline personality disorder, impaired cognitive development in infants and children), acne, asthma, exercise induced asthma, many types of cancers, macular degeneration, pre-term birth, psoriasis, insulin resistance, type 2 diabetes, cancer cachexia, intermittent claudication, skin damage from sunlight, IgA nephropathy, lupus erythematosus, type 1 diabetes, multiple sclerosis, and migraine headaches. (Shahar et al. 1994, Von Schacky et al. 1999 and Connor 2013).

\footnotetext{
${ }^{1}$ Department of Zoology, University of Dhaka, Dhaka, Bangladesh.

${ }^{2}$ Department of Biochemistry and Cell Biology, Bangladesh Institute of Research and Rehabilitation in Diabetes, Endocrine and Metabolic Disorders (BIRDEM) Dhaka, Bangladesh.

${ }^{3}$ IER, University of Dhaka, Dhaka, Bangladesh.

${ }^{4}$ Department of Biochemistry and Cell Biology, Bangladesh university of Health Science.
} 
In Bangladesh the fish ranks third after rice and vegetables in terms of weight of food consumed and the major dietary source is carbohydrate which intake daily per capita $384.00 \mathrm{gm}$ while the content of fat intake is $15.96 \mathrm{gm}$ daily per capita (Ahmad and Hasan 1983). Fishes are considered as an important source of fat with a balanced $\omega_{3}$ polyunsaturated composition which has beneficial effect on human health due to its most unique properties is not shared by any other foods (Evans et al. 1986 and Kinsella et al. 1987). The fish population declined in the last few decades, due to the urbanization, siltation of rivers and overexploitation to support the growing population. Therefore the PUFA intake was also declining. Recently, considering the nutritional value of fish and its important role in the social and economic life of the country, attention has been given in propagation and sustainability of fish. Among the fish populations the small indigenous fish species (SIS) are now attracting attention, due to their wide range of distribution, easy access to rural people and higher content of vitamin A, calcium and iron (Roos et. al. 2002). Moreover SIS is now cultured with large fishes which yield the higher production and also cost effective (Roos et al. 1999 and Kahinoor et al. 1994). The biological study and culture techniques have been done but detail study on their lipid compositions and its biological effects are relatively unknown from Bangladesh and elsewhere. The present attempt was made to assess the fatty acid compositions of three commonly available SIS viz. Mola (Amblypharyngodon mola), Jat Punti (Puntius sophore), and Shar Punti (Systomus sarana) of Bangladesh.

\section{METERIAL AND METHODS}

Sample collection and preparation: Fresh samples of three fish species were collected from the local fish market in early morning with proper icing and packaging in insulated containers and brought to the Advanced Fisheries Research Laboratory (AFRL), Department of Zoology, University of Dhaka for identification. After identification fishes were brought to biomedical research centre of BIRDEM for further analysis. The samples were washed in fresh water. The scales, fins, bones, viscera, gills were removed. Head was separated from body. The head and body were washed again with water separately and weighed. The head and edible body portion of each fish were grind to paste with the help of a blender.

Lipid extraction and methylation: Exactly $10 \mathrm{~g}$ of blended sample was taken from each fish sample for oil extraction. The extraction method was modified from Slover et al. (1987). For the preparation of methyl esters, the samples were saponified, the saponifiable matter was removed and the fatty acids were collected. The free acids were esterified with methanolic BF3. The extraction activities were carried out with atmospheric nitrogen flow. 
Gas chromatography (GC): The composition of fatty acids of their methyle esters were analyzed by a gas chromatography (GC). The GC (14 A Shimadzu Co, Tokyo, Japan) was fitted with a flame ionization detector and an automated electronic recorder (CR-5A chromatopack, Shimadzu Co., Tokyo, Japan). For fatty acid analysis a capillary glass column (50m X $0.25 \mathrm{~mm}$ ID) wall coated with 100\% Cyanopropyle PolySiloxane open tubular (WCTO) fused silica (SP2340, Supelco, Bellefonte, Pennsylvania, USA) was used, initial temperature of the column was $130^{\circ} \mathrm{C}$ with 4 minutes initial holding time, programmed to increase $3{ }^{\circ} \mathrm{C}$ per min to the $180^{\circ} \mathrm{C}$ in 5 min holding time. Finally, with the increase of 6 ${ }^{\circ} \mathrm{C} \mathrm{min}{ }^{-1}$ to the final temperature of $200^{\circ} \mathrm{C}$ for 10 minutes holding time. The flow rate of Helium gas was $3.5 \mathrm{ml}$ per minute with a split ration 1:60. Temperature of the injection port was $235^{\circ} \mathrm{C}$ and of the detector $240^{\circ} \mathrm{C}$. Fatty acid methyl esters of the three SIS were identified by comparison with the retention time of standard methyle esters and the amount were quantified from the integrated peak area as the percentage of the total area of all the peak. Each FAME in external will be identified by comparing retention times with those of known standard FAME (Cat. No. Lipid standard, Sigma Chemical Co, St Louis, Mo, USA)

\section{RESULTS AND DISCUSSION}

Total Lipid contents: The lipid contents of head and body part of A. mola, $P$. sophore and S. sarana are shown in Table 1 . The total lipid contents of the head of three SIS varied from 9.4 to $13.6 \%$ and of the body from 3.9 to $8.7 \%$. The highest content of total lipid of head part was recorded from sharputi (13.6\%), followed by Jat puti (10.2\%) and Mola (9.4\%). The highest content of total lipid from body parts was evident the Jatputi (8.7\%), followed by Sharputi $(6.25 \%)$ and Mola (3.9\%). Considering the three SIS, Mola constitute the lowest level of total lipids in head and body parts. The total lipid contents of head portion of all fishes were found to be higher than that of the body portion. Compare to some other researches on Indian halibut with the lipid level of $0.92 \%$ (Viswanathan et. al. 1978), Tenualosa ilisha with 8.5\% (Nuraini et. al. 2008), Sardinella lumuru head with $5.67 \%$ (Khoddami et al. 2009), the value of total lipid in the three examined fishes showed higher level.

Table 1. Lipid content (Mean \pm SD ) of Amblypharyngodon mola, Puntius sophore and Systomus sarana

\begin{tabular}{llll}
\hline \multicolumn{2}{l}{ Name of fishes } & \multicolumn{2}{l}{ Lipid content (\%) } \\
\cline { 3 - 4 } & & Head & Body \\
\hline Mola & Amblypharyngodon mola & $9.4 \pm 1.41$ & $3.9 \pm 0.14$ \\
Puti & Puntius sophore & $10.2 \pm 0.56$ & $8.7 \pm 0.42$ \\
Shar punti & Systomus sarana & $13.6 \pm 1.41$ & $6.25 \pm 1.06$ \\
\hline
\end{tabular}

$\%$ means $g$ per $100 \mathrm{~g}$ edible portion. 
Diversity of fatty acids: The fatty acids (FA) composition of the lipid extracted from head and body part of three studied fishes are shown in Table 2. Twenty one types of fatty acids were identified in body and head lipid of fishes were

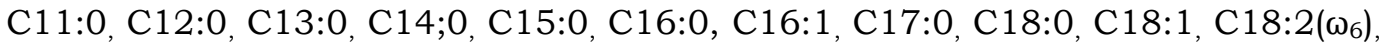
C18:3( $\left.\omega_{3}\right), C 18: 4\left(\omega_{6}\right), C 20: 0, C 20: 1, C 20: 2\left(\omega_{6}\right), C 20: 4\left(\omega_{6}\right), C 20: 5, C 22: 0, C 24: 0$, $\mathrm{C} 22: 6\left(\omega_{3}\right)$ and the fatty acids of the lipid were composed of saturated fatty acid, monounsaturated fatty acid and polyunsaturated fatty acid. The common fatty acids found in these fishes were palmitic (16:0), stearic (18:0), oleic (18:1), linoleic (18:2), linolenic (18:3), eicosapentaenoic acid (20:5) and docosahexaenoic acids (26:0).

Saturated fatty acids (SFAs): The total saturated fatty acids (SFAs), Monounsaturated fatty acids (MUFAs) and Polyunsaturated fatty acids (PUFAs) were shown in the Figure-1. The total SFAs content of head and body lipid of these fishes ranged between $34.8 \%$ to $74.01 \%$ which was highest in head lipid of $S$. sarana and lowest in body lipid of $P$. sophore. The value of saturated fatty acids were higher in the head lipid of $P$. sophore $(64.52 \%)$ and $S$. sarana $(74.02$ $\%$ ) than their body lipid which were respectively $34.84 \%$ and $44.14 \%$. Body lipid of A. mola contained higher amount of saturated fatty acid $(72.80 \%)$ than the head lipid (67.77\%). The predominant SFAs in the studied fishes were palmitic (16:0), stearic (18:0) and myristic acid (14:0). The highest levels of 16:0 $(39.88 \%), 18: 0(15 . .02 \%)$ and 14:0 (11.71\%) were determined in body lipid of $A$. mola, head lipid of $P$. sophore and Body of A. mola respectively.

Mono unsaturated fatty acids (MUFAs): The total mono unsaturated fatty acids (MUFA) of head and body lipid of three examined fishes were determined to be $11.02 \%$ (head lipid of $A$. mola) to $30.17 \%$ (body lipid of $S$. sarana). The main MUFAs identified in studied fishes were palmitolic acid (C16:1) and oleic (C18:1). The highest levels of $\mathrm{C} 16: 1$ (8.11\%) and C18:1(26.23\%)were determined in body lipid of $A$. mola and body lipid of $S$. sarana respectively. Considering the individual fatty acid, C18:1 was found as the second major fatty acid found in the three studied fish species varying from $6.64 \%$ to $26.23 \%$.

Table 2. Percentage of fatty acid composition (Mean \pm SD) of lipid of Amblypharyngodon mola, Puntius sophore, Systomus sarana

\begin{tabular}{lcccccc}
\hline \multirow{2}{*}{ Fatty acids } & \multicolumn{2}{c}{ A. mola $(n-3)$} & \multicolumn{2}{c}{ P. sophore $(n-3)$} & \multicolumn{2}{c}{ S. sarana(n-3) } \\
\cline { 2 - 6 } & Head & Body & Head & Body & Head & Body \\
\hline Saturated & & & & & & \\
C11:0 & & $0.25 \pm 0.19$ & & $0.05 \pm 0.02$ & & \\
C12:0 & $0.44 \pm 0.21$ & $0.84 \pm 0.20$ & $0.42 \pm 0.12$ & $0.31+0.01$ & $0.48 \pm 0.02$ & \\
C13:0 & $2.5 \pm 0.71$ & $1.75 \pm 0.26$ & & $0.13 \pm 0.01$ & $2.19 \pm 0.26$ & \\
\hline
\end{tabular}




\begin{tabular}{lcccccc}
\hline $\mathrm{C} 14: 0$ & $6.22+0.70$ & $11.71 \pm 0.47$ & $2.98 \pm 0.63$ & $1.58 \pm 0.26$ & $6.63 \pm 1.62$ & $2.37 \pm 0.08$ \\
$\mathrm{C} 15: 0$ & $7.95 \pm 1.42$ & $3.74 \pm 0.28$ & $2.17 \pm 0.08$ & $0.99 \pm 0.08$ & $6.33 \pm 0.07$ & $0.65 \pm 0.02$ \\
$\mathrm{C} 16: 0$ & $35.99 \pm 0.71$ & $39.88 \pm 0.26$ & $39.68 \pm 1.13$ & $16.86 \pm 3.83$ & $32.13 \pm 3.54$ & $27.01 \pm 2.08$ \\
$\mathrm{C} 17: 0$ & $2.79 \pm 0.70$ & $3.69+0.66$ & $3.87 \pm 1.02$ & $2.03 \pm 0.07$ & $2.52 \pm 0.15$ & $0.91 \pm 0.04$ \\
$\mathrm{C} 18: 0$ & $4.10+1.46$ & $8.04 \pm 0.74$ & $15.02+0.57$ & $7.54 \pm 2.00$ & $7.47 \pm 0.18$ & $7.35 \pm 1.76$ \\
$\mathrm{C} 20: 0$ & $1.9 \pm 1.90$ & $0.88 \pm 0.14$ & & & $16.23 \pm 0.61$ & $1.6 \pm 0.91$ \\
$\mathrm{C} 22: 0$ & $5.76 \pm 1.06$ & & $0.37+0.05$ & $2.12 \pm 0.71$ & & $4.18 \pm 1.1$ \\
$\mathrm{C} 24: 0$ & & $2.01 \pm 0.007$ & & $3.26 \pm 1.01$ & $0.04 \pm 0.01$ & \\
\hline Total Saturated & $67.77 \pm 1.59$ & $72.80 \pm 2.69$ & $64.52 \pm 3.46$ & $34.84 \pm 4.57$ & $74.01 \pm 1.1$ & $44.14 \pm 5.01$ \\
\hline
\end{tabular}

\begin{tabular}{|c|c|c|c|c|c|c|}
\hline Unsaturated & & & & & & \\
\hline MUFA & & & & & & \\
\hline C16:1 & $3.88 \pm 0.18$ & $8.11 \pm 0.41$ & $4.47 \pm 0.30$ & $1.53 \pm 0.3$ & $4.12 \pm 0.14$ & $3.22 \pm 1.1$ \\
\hline $\mathrm{C} 18: 1$ & $6.64 \pm 0: 71$ & $6.84+0.86$ & $21.29 \pm 4.89$ & $21.345 \pm 1.84$ & $11.6 \pm 0.05$ & $26.23 \pm 2.09$ \\
\hline C20:1 & & & & $1.095 \pm 0.09$ & & $0.72 \pm 0.01$ \\
\hline Total MUFA & $11.02 \pm 0.19$ & $14.94 \pm 1.27$ & $25.76 \pm 4.58$ & $23.97 \pm 1.58$ & $16.22 \pm 0.50$ & $30.17 \pm 2.2$ \\
\hline PUFA & & & & & & \\
\hline $\mathrm{C} 18: 2 \omega 6$ & $13.51 \pm 0.70$ & $0.19 \pm 0.01$ & $2.25 \pm 291$ & $9.49 \pm 0.32$ & $0.43 \pm 0.02$ & $8.74 \pm 1.01$ \\
\hline $\mathrm{C} 18: 3 \omega 3$ & & $1.61 \pm 028$ & $2.84 \pm 0.44$ & $2.87 \pm 0.43$ & $0.14 \pm 0$ & $0.15 \pm 0.01$ \\
\hline $\mathrm{C} 18: 4 \omega 3$ & & $0.3 \pm 0.12$ & & $6.75 \pm 0.26$ & $2.42 \pm 1.14$ & $0.013 \pm 0.03$ \\
\hline $\mathrm{C} 20: 2 \omega 6$ & $1.17 \pm 0.07$ & $5.80 \pm 0.84$ & $0.65 \pm 0.31$ & $6.745 \pm 0.03$ & $2.63 \pm 0.25$ & $0.42 \pm 0.10$ \\
\hline $\mathrm{C} 20: 4 \omega 6$ & $0.81 \pm 0.01$ & $0.15 \pm 0.07$ & $1.53 \pm 0.54$ & $6.89 \pm 2.54$ & $1.02 \pm 0.24$ & $8.91 \pm 2.01$ \\
\hline $\mathrm{C} 20: 5 \omega 3$ & $4.42 \pm 0.87$ & $0.17 \pm 0.07$ & $0.73 \pm 0.28$ & $5.49 \pm 2.29$ & $0.36 \pm 0.33$ & $3.38 \pm 1.4$ \\
\hline $\mathrm{C} 22: 6 \omega 3$ & $1.9 \pm 0.59$ & $3.84 \pm 0.82$ & $0.71 \pm 0.28$ & $2.755 \pm 0.98$ & $3.18 \pm 0.05$ & $2.70 \pm 1.2$ \\
\hline $\begin{array}{l}\text { Total } \\
\text { PUFA }\end{array}$ & $21.81 \pm 0.81$ & $12.08 \pm 1.65$ & $8.72 \pm 1.05$ & $40.99 \pm 6.23$ & $10.18 \pm 1.28$ & $24.31 \pm 5.76$ \\
\hline$\sum \omega 3$ & $6.31 \pm 1.4$ & $5.93 \pm 0.75$ & $4.28 \pm 1.01$ & $17.86 \pm 3.98$ & $6.1 \pm 0.76$ & $6.24 \pm 2.63$ \\
\hline$\sum \omega 6$ & $15.4 \pm 0.65$ & $6.15 \pm 0.90$ & $4.43 \pm 2.07$ & $23.12 \pm 1.59$ & $4.08 \pm 0.5$ & $18.06 \pm 3.12$ \\
\hline$\sum \omega 3 / \sum \omega 6$ & 0.42 & 0.97 & 0.97 & 0.77 & 1.50 & 0.35 \\
\hline
\end{tabular}

Total $\boldsymbol{\omega}_{\mathbf{3}}$ fatty acids included $\mathrm{C}_{18: 3}, \mathrm{C}_{18: 4}, \mathrm{C}_{20: 5}$ and $\mathrm{C}_{22: 6}$

Total $\boldsymbol{\omega}_{\mathbf{6}}$ fatty acids included $\mathrm{C}_{18: 2,}, \mathrm{C}_{20: 2}$, and $\mathrm{C}_{20}$ :

Polyunsaturated fatty acids (PUFAs): The principal PUFAs in the examined fishes were C18:2 $\omega_{6}, \mathrm{C} 18: 3 \omega_{3}, \mathrm{C} 18: 4 \omega_{3}, \mathrm{C} 20: 2 \omega_{6}, \mathrm{C} 20: 4 \omega_{6}, \mathrm{C} 20: 5 \omega_{3}, \mathrm{C} 22: 6$ $\omega_{3}$. The characteristic PUFAs which make fish oil as one of the important dietary components in the nutritional profile of human which were present in substantial quantity in the three studied fish species which were determined to 
be $8.72 \%$ in head lipid of $P$. sophore to $40.99 \%$ in body lipid of $P$. sophore. $(8.72$ to $40.99 \%$ ) in comparison with the native fish of Bangladesh, Hilsha (Tenualosa ilisha) with the value of 6.27 to $9.6 \%$ in summer (Jahan et al. 2000), Sardine, Sardinella lumuru head with 26.39\% (Khoddami et al. 2009) Spanish mackerel, Scomveromorus maculates with 22.27\% (Tawfic 2009), indian halibut (32.49\%) (Viswanathan et al. 1978).

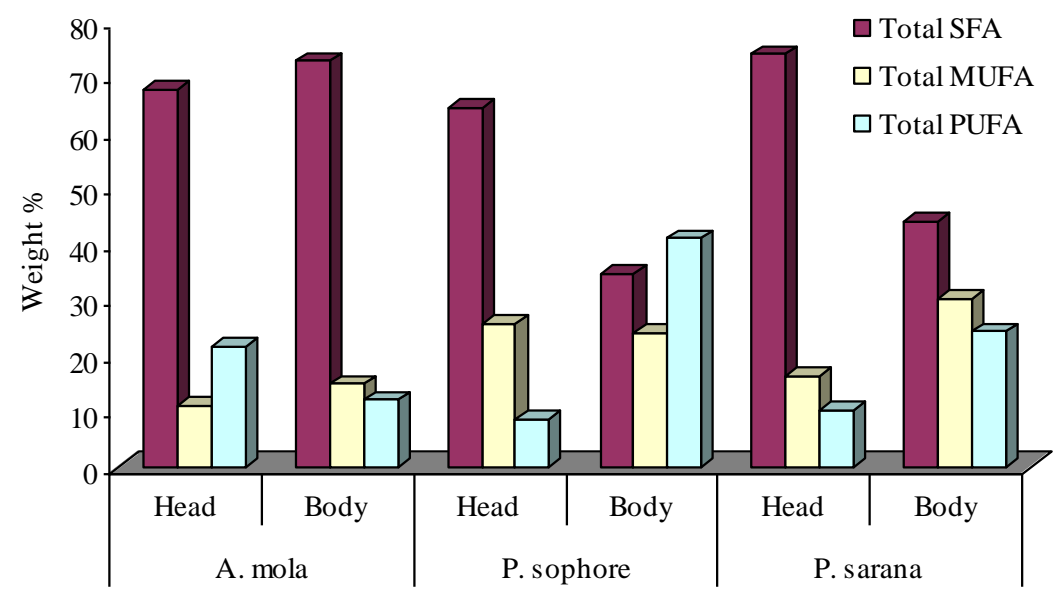

Fig. 1. Total Saturated fatty acid, Monounsaturated fatty acid and Polyunsaturated fatty acid (weight \%) of Amblypharyngodon mola, Puntius sophore and Systomus saranan

The total percentage of $\omega_{3}$ fatty acids in the three examined fish species had values between $17.86 \%$ in the body of $P$. sophore to $4.28 \%$ in the head of $P$. sophore shown in the Fig. 2.

Compare to some other researches, indicated that the $\omega_{3}$ PUFA content of examined fishes was within the range of some other fish such as Sardine head (17.79\%), Spanish mackerel (15.46\%), Red tilapia $(7.09 \%)$, African cat fish (1.19\%) shown in Table 3 (Khoddami et al. 2009, Tawfic 2009 and Suraiah et al. 1995).

Among $\omega_{3}$ series, the three examined fishes were good source of EPA and DHA. The fish lipids are characterized by their high proportion of PUFAs, such as the nutritionally important EPA and DHA, which are highly susceptible to autoxidation because of their high degree of unsaturation (Gunstone and Norris 1983)

Eicosapentaenoic acid C20:5 (EPA) showed an almost uniform distribution in the range of $0.17 \%$ in body lipid of $A$. mola to $5.49 \%$ in body lipid of $P$. sophore. The most abundant of the identified individual $\omega_{3}$ fatty acid appeared to be the Docoshexaaenoic acid C22:6 (DHA) showed an uniform distribution in the range of $1.9 \%$ in head lipid of $A$. mola to $3.84 \%$ in body lipid the same fish. 
Table 3. $\omega 3$ PUFA of lipid of Amblypharyngodon mola, Puntius sophore, Systomus sarana and some other fish species

\begin{tabular}{lcc}
\hline Fish name & Body part & $\begin{array}{c}\omega_{3} \text { PUFA (\% of the } \\
\text { total fatty acid) }\end{array}$ \\
\hline Amblypharyngodon mola & Head & $6.31 \pm 1.4$ \\
Puntius sophore & Body & $5.93 \pm 0.75$ \\
& Head & $4.28 \pm 1.01$ \\
Systomus sarana & Body & $17.86 \pm 3.98$ \\
& Head & $6.1 \pm 0.76$ \\
Sardine (Khoddami et al. 2009) & Body & $6.24 \pm 2.63$ \\
Spanish mackerel (Tawfik 2009) & Head & 17.79 \\
Red tilapia (Suraia et al. 1995) & Muscle & 15.46 \\
African Cat fish (Suraia et al. 1995$)$ & Muscle & 7.09 \\
\hline
\end{tabular}

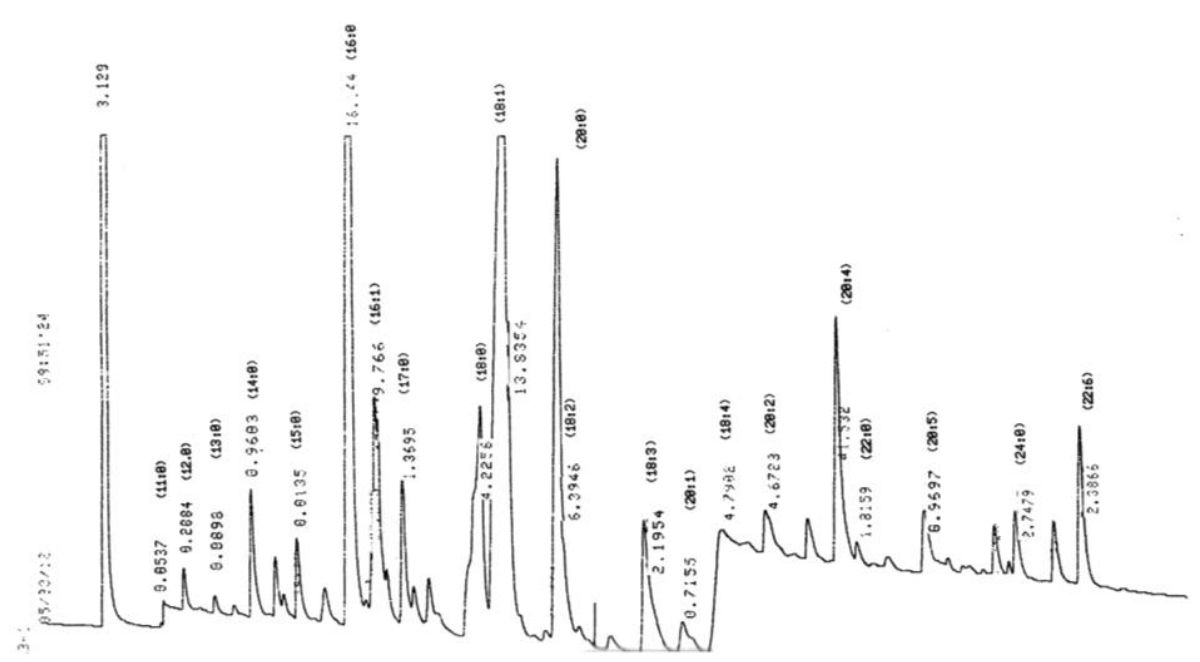

Fig. 2. Chromatogram of fatty acid of body of Puntius sophore.

The total percentage of $\omega_{6}$ varied from $4.08 \%$ to $23.12 \%$. The body of $P$. sophore appeared to contain the highest (23.12\%) and head of same fish contained lowest $(4.43 \%)$. Among $\omega_{6}$ PUFAs the C20:4 plays an important role in growth and is a precursor of prostaglandin and thromboxane (Suraiah et al. 1995). The 20:4 $\omega_{3}$ content of the examined fishes were in high level that were $0.15 \%$ to $8.91 \%$. 
The ratio between $\omega_{3}$ and $\omega_{6}$ is very useful index for comparing the nutritional value of fish lipid due to their human health effects on coronary heart disease, cancer and autoimmune diseases. It may be used for nutrient intake during human evolution as a 1:1 ratio (Simopoulos 1989). The ratios in the three examined SIS lipids were in good proportion that was between $0.35 \%$ to $1.50 \%$ shown in Table1. Therefore it need to be more focused on lipid extraction from Small indigenous fish species.

From the above discussion it is clear that the studied three small fishes of Bangladesh contained higher amount of fatty acids (weight\%) of lipid in comparison with some marine, freshwater and brackish water fishes in the region. Not only that the principal fatty acids, PUFAs especially the $\omega_{3}$ fatty acids which have the beneficial effect on health and diseases were found in higher quantity in comparison with other fishes and the ratio of $\omega_{3}$ and $\omega_{6}$ is also in good proportion. As the fishes contained higher lipid, this PUFAs will be available in higher quantity from small amount flesh of SIS in comparison with large fish. Therefore SIS are nutritionally very important for human health and good source of fatty acids specially PUFAs. As PUFAs have many beneficial effect on human health, the three examined SIS, Amblypharyngodon mola, Puntius sophore and Systomus sarana may have positive effect in improving the health of the nation where most of the people are poor and suffering from malnutrition.

Acknowledgements: Special thanks to the laboratory staffs at Advanced Fisheries Laboratory, Department of Zoology, University of Dhaka and also to the scientific officers, research fellows and laboratory staffs to the Biomedical Research Group, BIRDEM, Bangladesh for Providing laboratory facilities. We gratefully acknowledge the financial support of International Programm in the Chemical Science (IPSCS), Uppsala University, Sweden and Diabetic Association of Bangladesh (DAB) in conducting this study.

\section{LITERATURE CITED}

AHMAD, K. and HASAN, N. 1983. Nutrition survey of rural Bangladesh1981-1982. Institution of nutrition of food science. University of Dhaka, Bangladesh.

CONNOR, W. E. 2013. Importance of n-3 fatty acids in health and disease. Am. J. Clin. Nutr. 71(1): 171S-175S.

EVANS, A. J., FOGERTY, A. C. and SAINSBURY, K. J. 1986. The fatty acid composition of fish from the North- West shelf of Australia. CSIRO. Fd. Res. Quat. 46(2): 4045.

GUNSTONE, F. D. and NORRIS, F. P. 1983. Lipids in Food. Pergamon Press. New York.

JAHAN, S.S., MUSLEMUDDIN, M., HAQUE, M. S., and GOMES, B. 2000. Fatty acid composition of Hilsha Fish (Telualasa ilsha) at different conditions. South Asian J. Nutr. 2(1\&2): 29-34. 
Fatty acid composition of three small indigenous fishes

KHODDAMI, A., ARITTIN, A. A., BAKAR, J. and GHAZATI, H. M. 2009. Fatty acid profile of the oil extracted from fish waste (Head, intestine and liver) (Sardinella lemuru) World Applied Sciences Journal. 7(1): 127-131

KINSELLA, JE. 1987. Seafoods and Fish oils in human health and disease. In Marcel Dekker, Inc. New York and Basel. 317

KAHINOOR, A.H.M., HAQUE, M. Z. and GUPTA, M. V. 1994. Growth and survival of Thai punti (Puntius gonionotus) Spawn in nursary ponds at different stocking densities. $J$ Asiat. Soci. Bangladesh. 20(1): 65-72

NURAINI, J., NORZIAH, M.H., TAGALLY, B.Z., LIM, S. F., NORITA, M. and FAZILAH, A. 2008. Extraction of fish oil from fish waste from surimi processing plant. Int. Conference on Environmental Research and Technology (ICET)

ROOS, N., ISLAM, M. M., THILSTED S. H., ASHRAFUDDIN, M., MURSHEDUZZAM, M., MOHSIN, D. M. and SHAMSUDDIN, A.B.M. 1999. Culture of mola (Amblypharyngodon mola) in polyculture with carps Experience from a field trial in Bangladesh. NAGA- The ICLARM Quarterly. 22(2):16-19

ROOS, N., LETH, T., JAKOBSEN, J. and THILSTED, S. H. 2002. High Vitamin A content in some small indigenous fish species Bangladesh: perspectives for food-based strategies to reduce vitamin A deficiency. Int. J. Food Sci. Nutr. 53: 425-437

SHAHAR, E., FOLSOM, A.R., MELNICK, S.L., TOCHMAN, M.S., COMSTOCK, G.W., GENNARO, V., HIGGINS, M. W., SORLIE, P. D., KO, W. J. and SZKLO, M. 1994. Dietary n-polyunsaturated fatty acids and smoking related chronic obstructive . pulmonary disease. N. Engl. J. Med. 331 (4): 228-233

SIMOPOULOS, A. P. 1989. Summary of NATO advanced research workshop on dietary w3 and w-6 fatty acids: biological effects and nutritional essentiality. J. Nutr. 199: $512-528$

SLOVER, H. T., LANZA, E., THOMPSON, R. S., DAVIS, C. S. and MACROLA, G. 1987 Lipids in raw and cooked beef. J. Fd. Comp. Anal. 1: 26-37

SURAIAH, A. R., TEH, S. H., OSMAN, H. And NIK, M. D. 1995. Fatty acid composition of some Malaysian fresh water fish. Food Chemistry, 54:45-49

TAWFIC, M. S. 2009. Proximate composition and fatty acids profiles in most common available fish species in Saudi market. Asian J. Clinical Nutr. 1(1): 50-57

VISWANATHAN, P. G. and GOPAKUMAR, K. 1978. Fatty acid compositions of 15 species of fish from tropical waters. J. Food Sc. 43: 1162-1164

VON SCHACKY, C. P, ANGERER, W., KOTHNY, K., THEISEN and UDRE, H. 1999. Effect of dietary omega-3 fatty acids on coronary atherosclerosis: A randomized doubleblind placebo-controlled trial. Ann. Int. Med. 130 (7): 554-562 